Article

\title{
Analysis of the Primary Building Materials in Support of G-SEED Life Cycle Assessment in South Korea
}

\author{
Hyojin Lim ${ }^{1}$, Sungho Tae ${ }^{2, *}$ and Seungjun Roh $^{3, *}$ \\ 1 Department of Architectural Engineering, Hanyang University, 55 Hanyangdaehak-ro, Sangrok-gu, \\ Ansan 15588, Korea; hjlimc@hanyang.ac.kr \\ 2 Department of Architecture \& Architectural Engineering, Hanyang University, 55 Hanyangdaehak-ro, \\ Sangrok-gu, Ansan 15588, Korea \\ 3 Sustainable Building Research Center, Hanyang University, 55 Hanyangdaehak-ro, Sangnok-gu, \\ Ansan 15588, Korea \\ * Correspondence: jnb55@hanyang.ac.kr (S.T.); roh.seungjun@gmail.com (S.R.); Tel.: +82-31-400-5187 (S.T.); \\ $+82-31-436-8076$ (S.R.)
}

Received: 4 June 2018; Accepted: 4 August 2018; Published: 9 August 2018

\begin{abstract}
In recent years, much research has been conducted internationally to quantitatively evaluate the environmental impact of buildings in order to reduce greenhouse gas emissions and address associated environmental problems. With this in mind, the Green Standard for Energy and Environmental Design (G-SEED) in South Korea was revised in 2016. However, the various possible evaluation methods make it difficult to conduct building life cycle assessment. Moreover, compared to research on residential buildings, life cycle assessment research on non-residential buildings is scarce. Therefore, this study analyzes primary building materials for life cycle assessment of current non-residential buildings to support Korean G-SEED requirements. Design documents for various non-residential buildings are obtained, and the types and numbers of materials used in production are determined. Next, the primary building materials contributing high cumulative weight based on the ISO14040 series of standards are analyzed. We then review the most commonly-used building materials while considering non-residential building types and structures. In addition, construction material reliability is evaluated using the environmental impact unit value. With our results, by suggesting the primary building materials in non-residential buildings, efficient life cycle assessment of non-residential buildings is possible in terms of time and cost.
\end{abstract}

Keywords: primary building materials; life cycle assessment; G-SEED

\section{Introduction}

In recent years, the number of environmental incidents has increased globally. Currently, many countries have adopted the Paris Agreement (COP21, 2015), which specifies targets for the reduction of greenhouse gas emissions, and each signatory country is now introducing various policies and developing advanced technologies to comply with the agreement [1,2]. In particular, according to the "Basic Plans in Response To Climate Change" document published in South Korea in 2016, when interest in environmental problems caused by buildings was escalating, the target reduction in emissions for the construction sector was set to $18.1 \%$ (approximately 56.4 million tons) of business as usual (BAU) values. The construction sector is the second-highest emitter of greenhouse gas among the industrial sectors. To meet the aforementioned target, various policies have been implemented, including the Green Building Support Law and the Basic Plans for Green Buildings. Governments in the United Kingdom (U.K.), the United States (U.S.), Germany and Switzerland, which are leading 
countries in environmental regulations, have introduced their own green building certification systems (LEED, BREEAM, DGNB and Minergie) to reduce greenhouse gas emissions in the construction sector. These systems include building life cycle assessment (LCA) certifications that serve to reinforce the certification criteria gradually. Building LCA is a method for quantitatively predicting and assessing the total emissions that may result from the building materials over the entire life cycle (production, construction, operation and disposal) of a building. Studies are currently underway to determine how to reduce the greenhouse gas emissions discharged from buildings through such assessments.

The Green Standard for Energy and Environmental Design (G-SEED) is the green building certification system of South Korea. While it created building LCA certification items when its certification criteria were revised in 2016, the law alone cannot ensure proper implementation of an LCA; thus, supplementary measures are urgently required. Since a building consists of numerous types and quantities of building materials, it is difficult to properly assess these items during the design and production stage of a building due to the frequency of design changes and limited available information. Therefore, at present, conducting an LCA is expensive in terms of time and financial cost, and certifications that use the building LCA are extremely rare.

Hence, this research aims to analyze the main building materials that may apply during life cycle assessment of non-residential buildings to support G-SEED life cycle assessment of buildings.

To achieve this aim, various kinds of pre-existing buildings with different building types and structures are set as the subjects of evaluation; then, the types and numbers of materials invested during the production stage are determined. Next, the main building materials are analyzed according to ISO14040s and the internal life cycle assessment analysis method. Then, the applicable main building materials are set according to building types and structures during life cycle assessment of buildings in G-SEED, and their applicability is examined [3-8]. This study is conducted as per the sequence shown in Figure 1 to support the building LCA of G-SEED. The greenhouse gas emissions status, content of the building LCA and current research trends in the construction sector are analyzed, and the primary building materials that must be evaluated to conduct an LCA are derived. Then, guidelines for the building LCA are proposed via several scenarios, and the reliability of the corresponding predictions is examined by analyzing the environmental impact of the selected primary building materials.

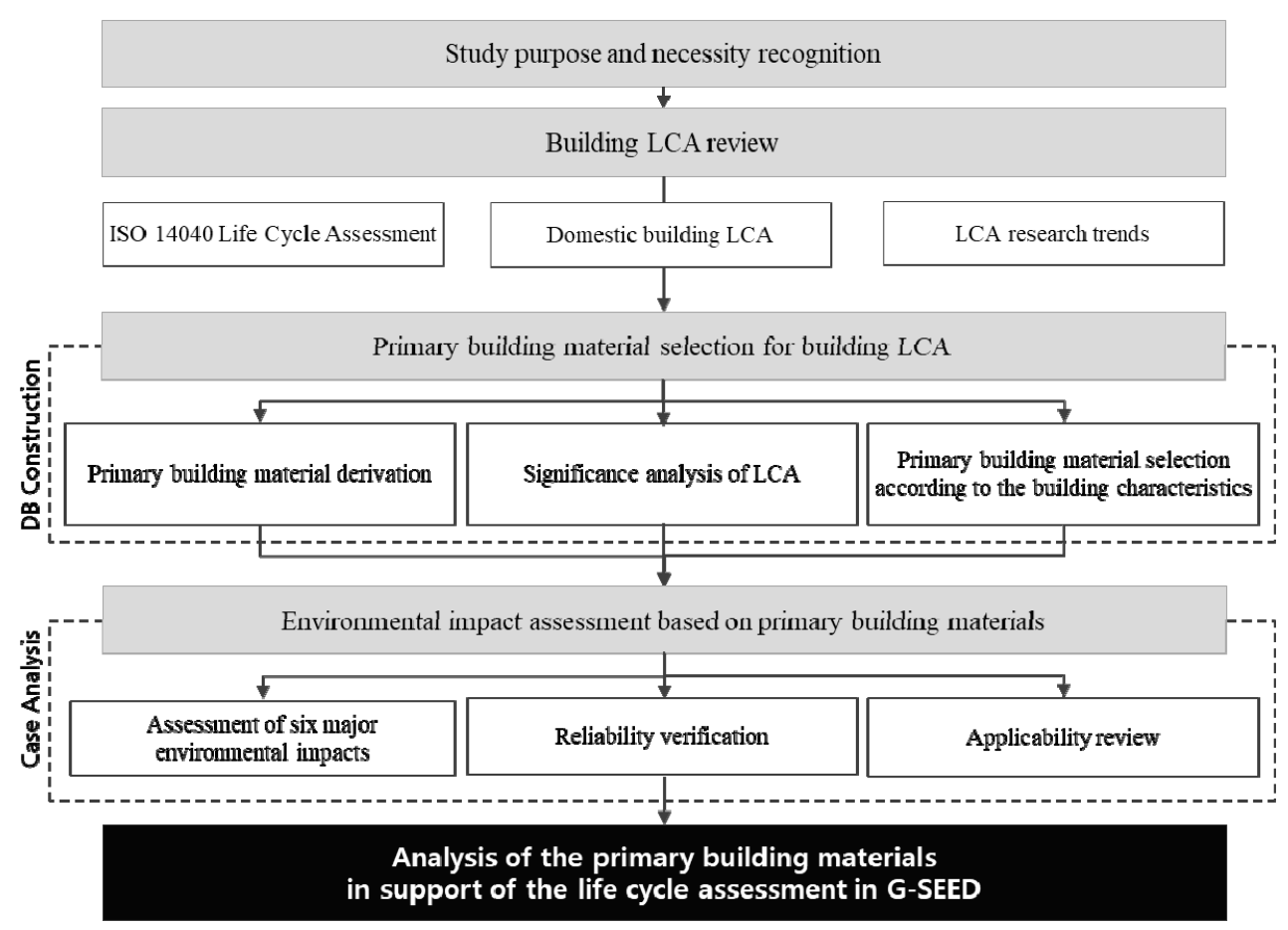

Figure 1. Study flowchart. 


\section{Literature Review}

G-SEED [8,9] can be used when assessing and certifying the environmental impact of a building in order to reduce its use of energy and resources, as well as its environmental burden. The latter includes considerations like pollutant emissions, which may arise from the life cycle of the building throughout the material production, design, construction, maintenance and disposal stages. This standard originated from the eco-friendly building certification for apartment housing initiated by the Ministry of Land, Infrastructure and Transport (MOLIT) and the Ministry of Environment (ME) in 2002 and was revised in 2013 under the name of G-SEED to assess the eco-friendliness of buildings from an integrated perspective. G-SEED outlines the requirements for certification in four grades, namely normal, good, excellent, and best. New and existing buildings can be assessed after they have been classified into one of five non-residential building types (general buildings, office buildings, school buildings, commercial buildings and accommodation buildings) or three residential building types (general housing, apartment housing and single-family housing). The assessment criteria for each specialized area are based on eight categories: land use, transportation, energy, environmental pollution, materials and resources. The innovative design area, which was newly added in the revision of 2016, provides several additional categories for scoring such as zero-energy buildings and environmental management of a green construction site. G-SEED is continuously being revised to reflect international trends, and its certification criteria have been gradually reinforced with the intent to develop it into both a domestic and international certification system in the future. The status of green building certification according to building construction year is shown in Figure 2. As shown, the number of green building certifications has surged recently, with cumulative total certification cases reaching 7968 as of 2016. Notably, as shown in Figure 2, non-residential buildings were far more likely to be certified than residential buildings, representing approximately $66 \%$ of preliminary certification applications and $74 \%$ of those seeking main certification among all applications for certification, even though certification of these types has been available since 2010 .

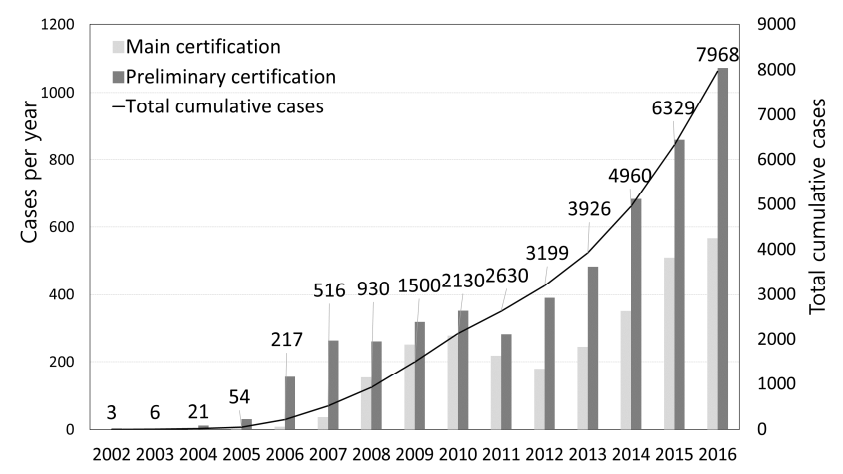

(a)

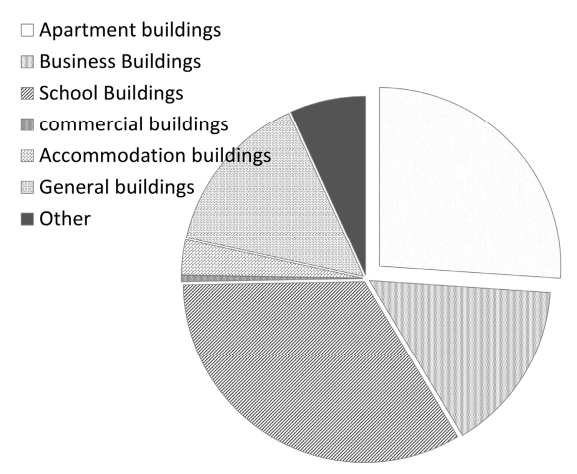

(b)

Figure 2. Status of green building certification. (a) Green building certification by year [9]; (b) certification status by building use (2002-2017) [9].

The innovative design area was introduced to the G-SEED certification system in the revision of 2016. In this supplement, the need for a building LCA is assessed in terms of material and resources. The building LCA has been designated as an assessment item to encourage the establishment of plans to reduce the environmental burden in each life cycle stage of a building. It is possible to receive additional points when a grade of excellent (green 2 grade) or above is requested. LCA is classified into a streamlined LCA and a regular LCA. In an assessment, one point is awarded when a streamlined LCA is performed and two points when a regular LCA is performed. A building LCA covers all processes from the production of building materials to the construction, use and dismantling of the building. LCA in G-SEED was assessed based on ISO14040s in the same way as LEED and evaluating the environmental effect of principal building materials: those within a $99 \%$ cut-off based on weight 
among building materials used during the production stage. The environmental effect assessment was performed using the deduced main building materials as the objects of study, and two points were given when the minimum of three types of environmental effects were assessed, including global warming within the six environmental effect categories, global warming, ozone depletion, eutrophication, resource depletion, acidification, etc.

To outline LCA, which was awarded one point, up to ten main materials including concrete, cement and reinforced steel were specified as the subjects of evaluation. Additionally, the point would be given when the global warming potential (greenhouse gas emission quantity) out of six environmental effect categories was clearly included in the environmental effect assessment. On the other hand, in LEED, points would be given when performing a building life cycle assessment, and a certain quantity of material was reduced compared to the baseline building using a minimum of three kinds of environmental effect categories as the objects. Compared to LEED, points could be received only by conducting life cycle assessment in G-SEED. However, the wording given in the outline life cycle assessment could be interpreted as meaning either one or ten materials. As a result, problems related to the current wide range of evaluation and methods arose. In the case of life cycle assessment, the main building materials within the $99 \%$ cut-off based on weight had to be deduced for every assessment. Therefore, it was time-consuming and difficult to judge these objectively. This brought substantial confusion for the appraisers, and the number of life cycle assessments of buildings performed since the revision seems very small.

Although the number of studies researching the LCA of non-residential buildings has slowly increased, most have been limited to energy at the operation stage and have had a restricted research scope. In particular, although many studies on effectiveness verification, assessment item analysis and application methods for domestic green building certification systems have been conducted since the G-SEED revision in 2016, the number of studies on the practical implementation of G-SEED remains extremely low. To address this, it is necessary to analyze the primary building materials while considering building characteristics such as the building and structural type and to propose corresponding LCA guidelines so that building LCAs can be performed in accordance with the domestic green building certification system [10-28].

\section{Analysis Method of the Primary Building Materials}

\subsection{Overview}

Figure 3 shows the system boundary and assessment scope of this study. As shown in the figure, the building materials used in non-residential buildings were analyzed to support a streamlined LCA in accordance with the domestic green building certification system, which is the overall objective of this study. The data for the primary building materials was organized as specified by the streamlined LCA. For this, the design details and supply sheets of non-residential buildings were collected, from which ten primary building materials were derived based on the LCA method specified by the international standard of ISO 14040s. In addition, the scope of the streamlined LCA was assessed by significance analysis of building materials corresponding to the $95 \%$ cut-off criterion suggested by the LCA guidelines, and the primary building materials to be assessed were classified and selected according to the characteristics of the building. On this occasion, the function of this evaluation standard is type of buildings (school, office, accommodation, general and commercial), and the functional unit is the unit area $\left(\mathrm{m}^{2}\right)$ of building to be used for 50 years. An overview of the 16 non-residential buildings analyzed in this study is shown in Table 1. In the table, the term RC denotes a reinforced concrete structure and SRC denotes a steel-reinforced concrete structure. 


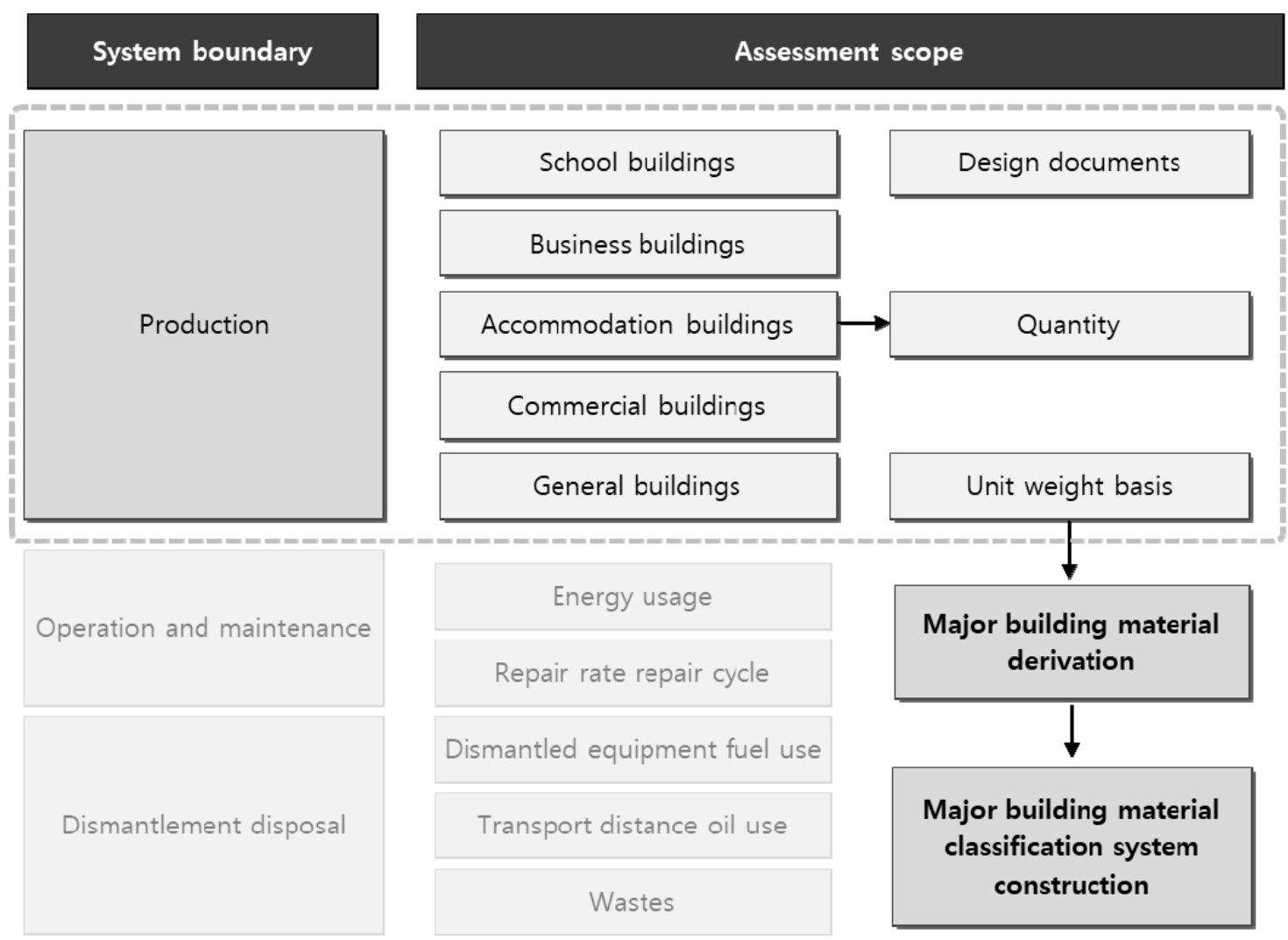

Figure 3. Analysis target and scope.

Table 1. Synopsis of analyzed buildings. SRC, steel-reinforced concrete.

\begin{tabular}{ccccc}
\hline Division & Location & Building & Structure & Total Floor Area $\mathbf{( m}^{\mathbf{2}} \mathbf{~}$ \\
\hline Case 1 & South Korea & School & RC & 6950 \\
Case 2 & South Korea & School & RC & 10,190 \\
Case 3 & South Korea & School & RC & $11,963.11$ \\
Case 4 & South Korea & Office & SRC & 18,690 \\
Case 5 & South Korea & Office & SRC & $36,368.06$ \\
Case 6 & South Korea & Office & SRC & $59,826.39$ \\
Case 7 & South Korea & Office & RC & 3817 \\
Case 8 & South Korea & Office & RC & 3819.68 \\
Case 9 & South Korea & Accommodation & RC & $41,153.02$ \\
Case 10 & South Korea & Accommodation & RC & 32,968 \\
Case 11 & South Korea & General & RC & 17,161 \\
Case 12 & South Korea & General & RC & 5280.27 \\
Case 13 & South Korea & General & RC & 31,699 \\
Case 14 & South Korea & General & RC & 6646 \\
Case 15 & South Korea & Commercial & SRC & $130,007.3$ \\
Case 16 & South Korea & Commercial & SRC & 1113,453 \\
\hline
\end{tabular}

\subsection{Analysis Method for Primary Building Materials}

To select the primary building materials used in non-residential buildings as per the scope of this study, the design details and supply sheets of 16 buildings corresponding to the five types of non-residential buildings specified by G-SEED, namely schools, offices, accommodation, commercial and general buildings, were collected. Then, the primary building materials that had a high cumulative weight contribution were analyzed in accordance with the weight-based cut-off criteria analysis method as applied in an LCA [29]. This is a standard analysis method specified by ISO14040s and refers to the 
quantitative criteria that can be excluded from the input investigation process of an LCA to facilitate its performance. In this case, 95 or $99 \%$ of the total weight is usually applied [30,31].

The construction scope was classified based on the design details and supply sheets of the 16 selected non-residential buildings, and the amounts of building materials involved in the construction were identified. After these were converted to weight units, the primary building materials corresponding to the cumulative weight criterion of $95 \%$ were analyzed in accordance with the cut-off criteria in an LCA. Since the supply sheets of the buildings used different units for each material, the units of all the building materials were converted to a common weight unit (ton) to improve consistency. These were then converted to weight per unit area (ton $/ \mathrm{m}^{2}$ ) when the significance of the primary building materials was examined for each building. For the building unit conversion coefficients used for the weight unit conversion, the domestic construction standard estimates, construction specifications and metal specific gravity table were consulted. The temporary materials, including the formwork, floor posts and safety materials used for temporary construction were excluded from the system boundary of this study because all of these were collected after use and reused at the construction sites of other buildings. In addition, accessory materials and work by-products representing less than $0.01 \%$ of the total weight of the building materials used for non-residential building construction were excluded from the scope of analysis [32,33]. Examples of the building material unit conversion coefficients used in this study are shown in Table 2 [34].

Table 2. Unit weight per building material (partial).

\begin{tabular}{cccc}
\hline Materials & Unit Weight & Unit & Source \\
\hline Reinforced Concrete & 2400 & $\mathrm{~kg} / \mathrm{m}^{3}$ & Construction Standard [34] \\
Plain Concrete & 2300 & $\mathrm{~kg} / \mathrm{m}^{3}$ & Construction Standard [34] \\
Cement Mortar & 2100 & $\mathrm{~kg} / \mathrm{m}^{3}$ & Construction Standard [34] \\
Cement & 40 & $\mathrm{~kg} / \mathrm{bag}$ & Construction Standard [34] \\
Wood & 800 & $\mathrm{~kg} / \mathrm{m}^{3}$ & Construction Standard [34] \\
Glass & 2500 & $\mathrm{~kg} / \mathrm{m}^{3}$ & Construction Specification [34] \\
\hline
\end{tabular}

\section{Analysis Results for Primary Building Materials}

\subsection{Results for Primary Building Material Analysis}

To derive a list of the ten primary building materials required by the streamlined LCA method stipulated in G-SEED, the primary building materials for 16 non-residential buildings were investigated by applying the $95 \%$ cut-off criterion to the input materials. Figure 4 shows the weight-based primary building material analysis results. The graph is based on the cumulative weight contribution corresponding to the 95\% cut-off criterion. As shown in Figure 4, the weight proportions and ranks of the primary building materials were somewhat different depending on the size, total floor area and type of building. Based only on the building material type, the common materials in all non-residential buildings included ready-mixed concrete, rebar, concrete and bricks. Among these, ready-mixed concrete was a primary building material that accounted for the highest proportion (more than 60\%) in all cases and exhibited the highest weight contribution.

Furthermore, a classification system of the derived primary building materials was established through a significance examination and analysis as to whether the types and structural types of the non-residential buildings affected the primary building materials. On this basis, the primary building materials in non-residential buildings applicable to the streamlined LCA of G-SEED were identified [35]. 


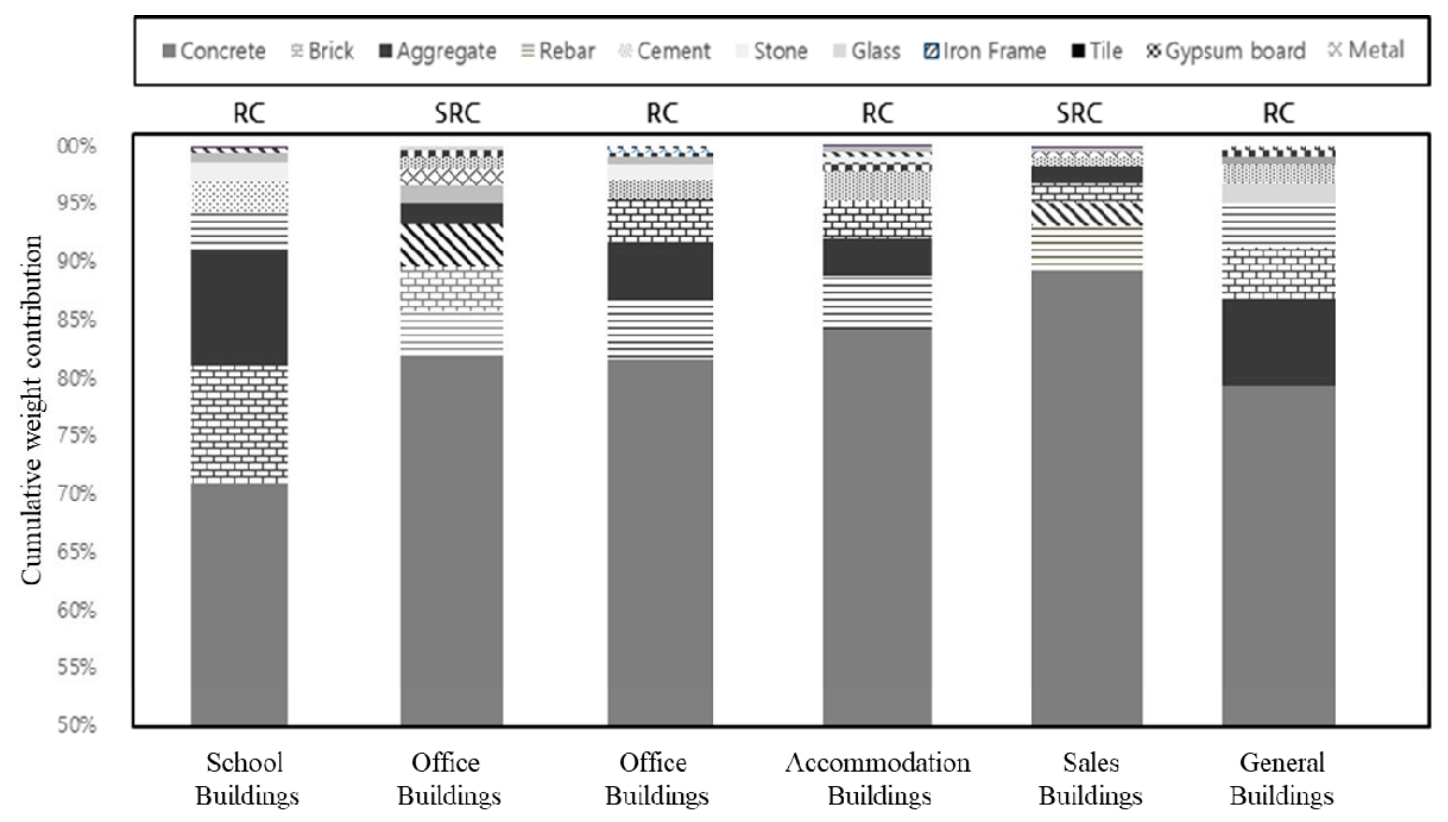

Figure 4. Cumulative weight contribution of primary building materials.

\subsection{Primary Building Materials by Usage According to Significance Analysis}

Figure 5 shows a graph for the cumulative weight contribution of the primary building materials for school and office buildings. From the figure, since most school buildings were modularized according to the RC structural type, concrete, bricks, aggregate, rebar and cement were derived as the primary building materials in all cases when the 95\% cut-off criterion was applied. In the case of office buildings, the amount of bricks was lower than that in school buildings; however, the weight contribution of the concrete and rebar was higher. This means that the amounts of primary building materials varied depending on the type of building. Furthermore, from the viewpoint of the structural types of office buildings, the iron frame was included in the primary building materials in the SRC structure, but was not included in the primary building material of the RC structure when the $95 \%$ cut-off criterion was applied. In addition, it was confirmed that the SRC structure consumed more glass than did the RC structure. This indicates that the inclusion of the iron frame and glass varied depending on the structural format despite being for the same building type. Thus, both the building type and the structural format must be considered in the selection of primary building materials. Therefore, in this study, primary building materials, of which there must be less than ten, were classified and selected considering both the building type and structural format based on the building usage classification system in G-SEED. This can be utilized as an assessment index and tool for selecting primary building materials in the building-streamlined LCA of G-SEED. Based on the selected primary building materials, it is expected that the life cycle emissions of a building throughout the production, construction, operation and disposal stages can be quantitatively assessed. 


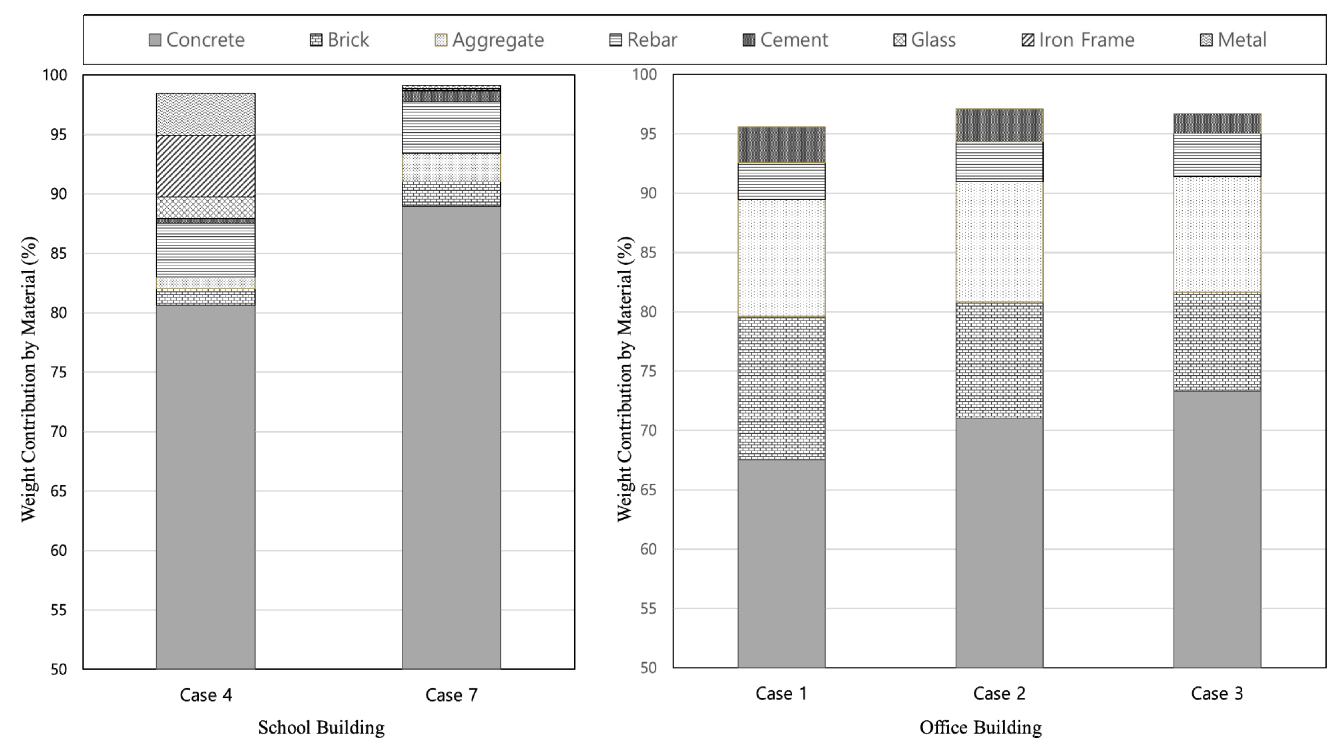

Figure 5. Contribution of the cumulative weight of the primary building materials.

\subsection{Selection of Primary Building Materials}

Figure 6 shows the primary building materials of the constructed non-residential buildings considering the building usage and structural format based on the building usage classification system specified in G-SEED. The intent of this study is to specify primary building materials that can be used for the streamlined LCA process of non-residential buildings in support of building LCA in G-SEED. With this in mind, the primary building materials in non-residential buildings that exceeded the $95 \%$ cut-off criterion were selected in accordance with the building use or structural type, as shown in Figure 6. The selected primary building materials were comprised of five items, namely concrete, concrete bricks, aggregate, rebar and cement for school buildings in the RC structure; five items, namely concrete, rebar, aggregate, bricks and cement for office buildings in the RC structure; six items, namely concrete, rebar, bricks, iron frames, aggregate and glass for office buildings in the SRC structure; five items, namely concrete, rebar, aggregate, bricks and cement for accommodation buildings in the RC structure; four items, namely concrete, rebar, iron frames and bricks for commercial buildings in the SRC structure; and six items, namely concrete, aggregate, bricks, rebar, cement and stone for general buildings. If the selected primary building materials are applied to the streamlined LCA, then it is possible to provide efficient assessments in terms of both time and cost.

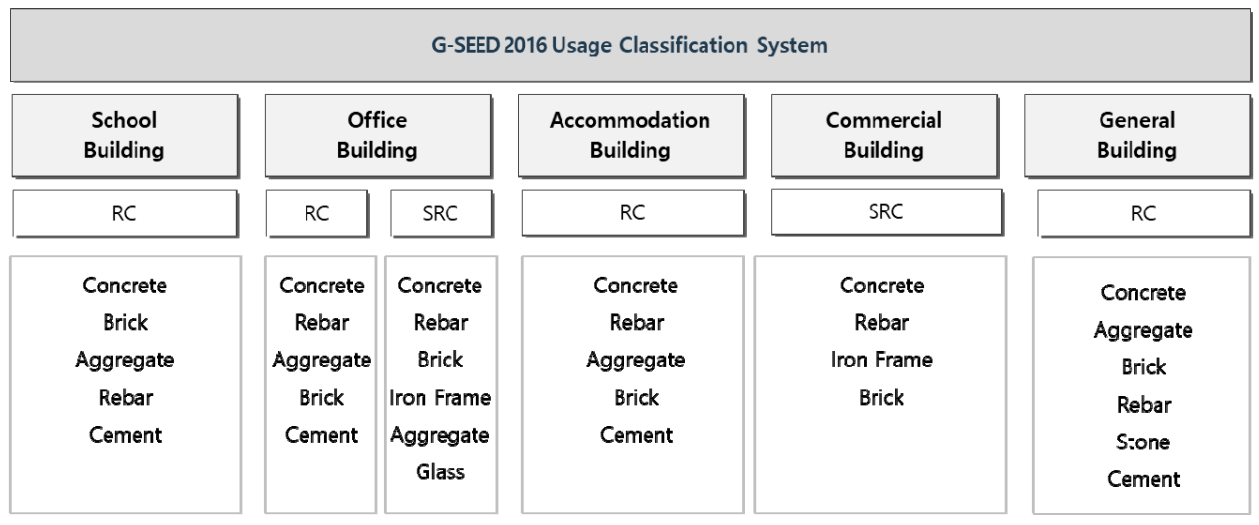

Figure 6. Classification of primary building materials with building type. 


\section{Case Analysis}

\subsection{Overview}

In this section, a life cycle environmental impact assessment is performed by applying the environmental impact unit value to the identified primary building materials to verify the reliability of the study. In addition, the environmental impact values of all building materials are analyzed by comparison with the primary building materials.

\subsection{Analysis Target and Method}

The case assessment was conducted for a school building with an RC structure located in South Korea. Based on the primary building materials of constructed school buildings in the RC structure, a life cycle environmental impact assessment was performed for the six environmental impact categories, namely GWP, AP, ADP, EP, ODP and POCP, as specified by ISO14025 as the primary environmental impact categories. In this case, for environmental impact characterization values of the building materials, the national LCI DB constructed by the Ministry of Environment and the Ministry of Trade, Industry and Energy and the building material environmental impact information national DB constructed by the Ministry of Land, Infrastructure and Transportation were applied. The environmental impact characterization value of each building material was derived using the following equation.

$$
\mathrm{CO}_{2}=\Sigma \mathrm{M}_{i j} \times \text { Basic Unit }{ }_{i, \mathrm{CO}_{2}}
$$

Here, $M_{i j}$ represents the usage of the building material (j) by construction type (i) (unit $/ \mathrm{m}^{2}$ ) and Basic Unit ${ }_{i, \mathrm{CO}_{2}}$ represents the $\mathrm{CO}_{2}$ emissions unit value for building material (j) (kg- $\mathrm{CO}_{2} / \mathrm{unit}$ ).

Table 3 shows examples of the six environmental impact characterization values versus the building material [36].

\subsection{Analysis Result}

A graph showing the contributions to the six environmental impacts is shown in Figure 7. According to the graph, the total amounts of emissions in each environmental impact category were $4.3 \times 10^{6} \mathrm{~kg}-\mathrm{CO}_{2 \text { eq }}$ for GWP, $1.7 \times 10^{4} \mathrm{~kg}-\mathrm{Sb}_{\mathrm{eq}}$ for ADP, $9.5 \times 10^{3} \mathrm{~kg}$-CFC- $11_{\mathrm{eq}}$ for AP, $1.6 \times 10^{3}$

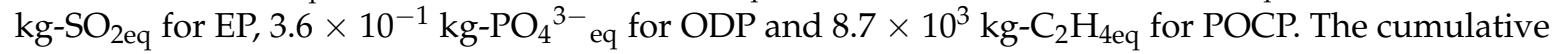
contribution of the five primary building materials to each of the six environmental impact categories for the streamlined LCA was $91.82 \%$ for GWP, $63.76 \%$ for ADP, $78.83 \%$ for AP, $58.78 \%$ for EP, $96.51 \%$ for ODP and $92.68 \%$ for POCP. This confirms that deriving the primary building materials based on the weight resulted in error rates less than $5 \%$ when evaluating the environmental impact assessment for GWP, ODP and POCP. However, it was also found that the primary building materials alone were not sufficient to assess environmental impacts in the case of AP, EP and ADP. As such, the contributions of each material to the six environmental impact categories were confirmed, and the results facilitate an accurate environmental impact assessment for all six environmental impact categories in the future. A graph showing the contributions of each material to the six environmental impact categories is shown in Figure 8. As shown in the figure, ready-mixed concrete, which had the highest contributions based on weight, exhibited high contributions only for GWP, ODP and POCP and showed low contributions for the other environmental impact categories. In addition, materials with high contributions were different depending on the environmental impact categories. Insulating materials in particular made almost no contribution based on weight, but exhibited high contributions to the AP. Therefore, to assess all six environmental impact categories using the $95 \%$ criterion, it was necessary to identify the primary building materials with high environmental impacts that are at risk of being excluded by the weight-based analysis method in addition to identifying primary building materials based on weight. 
Table 3. Environmental impact characterization values by building material (partial).

\begin{tabular}{|c|c|c|c|c|c|c|c|}
\hline \multirow{3}{*}{ Building Material } & \multirow{3}{*}{ Unit } & \multicolumn{6}{|c|}{ Six Environmental Impact Characterization Values by Building Material [36] } \\
\hline & & GWP & ADP & AP & EP & ODP & POCP \\
\hline & & kg-CO ${ }_{2 e q} /$ Unit & kg-Sb eq /Unit & kg-CFC-11 $1_{\mathrm{eq}} /$ Unit & $\mathrm{kg}-\mathrm{SO}_{2 \mathrm{eq}} /$ Unit & kg-PO ${ }_{4}{ }^{3-}$ eq $/$ Unit & $\mathrm{kg}-\mathrm{C}_{2} \mathrm{H}_{4 \mathrm{eq}} / \mathrm{Uni}$ \\
\hline Unsaturated polyesters & $\ell$ & $2.87 \times 10^{0}$ & $3.62 \times 10^{-2}$ & $7.14 \times 10^{-3}$ & $6.56 \times 10^{-4}$ & $9.35 \times 10^{-7}$ & $2.48 \times 10^{-3}$ \\
\hline Water-soluble emulsion & $\ell$ & $3.23 \times 10^{-1}$ & $6.49 \times 10^{-3}$ & $1.13 \times 10^{-3}$ & $9.53 \times 10^{-5}$ & $8.51 \times 10^{-8}$ & $4.05 \times 10^{-4}$ \\
\hline Water-soluble liquid & $\ell$ & $1.19 \times 10^{0}$ & $1.48 \times 10^{-2}$ & $7.62 \times 10^{-3}$ & $9.99 \times 10^{-4}$ & $2.71 \times 10^{-8}$ & $4.04 \times 10^{-4}$ \\
\hline Amino alkyd paint & $\ell$ & $8.37 \times 10^{-1}$ & $1.80 \times 10^{-2}$ & $3.77 \times 10^{-3}$ & $1.83 \times 10^{-3}$ & $4.06 \times 10^{-8}$ & $3.65 \times 10^{-4}$ \\
\hline Alkyd-enamel & $\ell$ & $2.26 \times 10^{-1}$ & $2.42 \times 10^{-2}$ & $1.63 \times 10^{-3}$ & $1.18 \times 10^{-4}$ & $2.03 \times 10^{-8}$ & $1.82 \times 10^{-4}$ \\
\hline Plate glass & ton & $7.88 \times 10^{2}$ & $6.97 \times 10^{0}$ & $3.67 \times 10^{0}$ & $5.23 \times 10^{-2}$ & $3.04 \times 10^{-4}$ & $8.95 \times 10^{-1}$ \\
\hline Double glazing & $\mathrm{m}^{2}$ & $2.24 \times 10^{1}$ & $9.13 \times 10^{-2}$ & $3.05 \times 10^{-2}$ & $2.21 \times 10^{-3}$ & $1.81 \times 10^{-7}$ & $5.39 \times 10^{-2}$ \\
\hline Tempered glass & $\mathrm{m}^{2}$ & $1.34 \times 10^{1}$ & $5.19 \times 10^{-2}$ & $2.57 \times 10^{-2}$ & $4.05 \times 10^{-3}$ & $6.64 \times 10^{-8}$ & $1.43 \times 10^{-2}$ \\
\hline
\end{tabular}




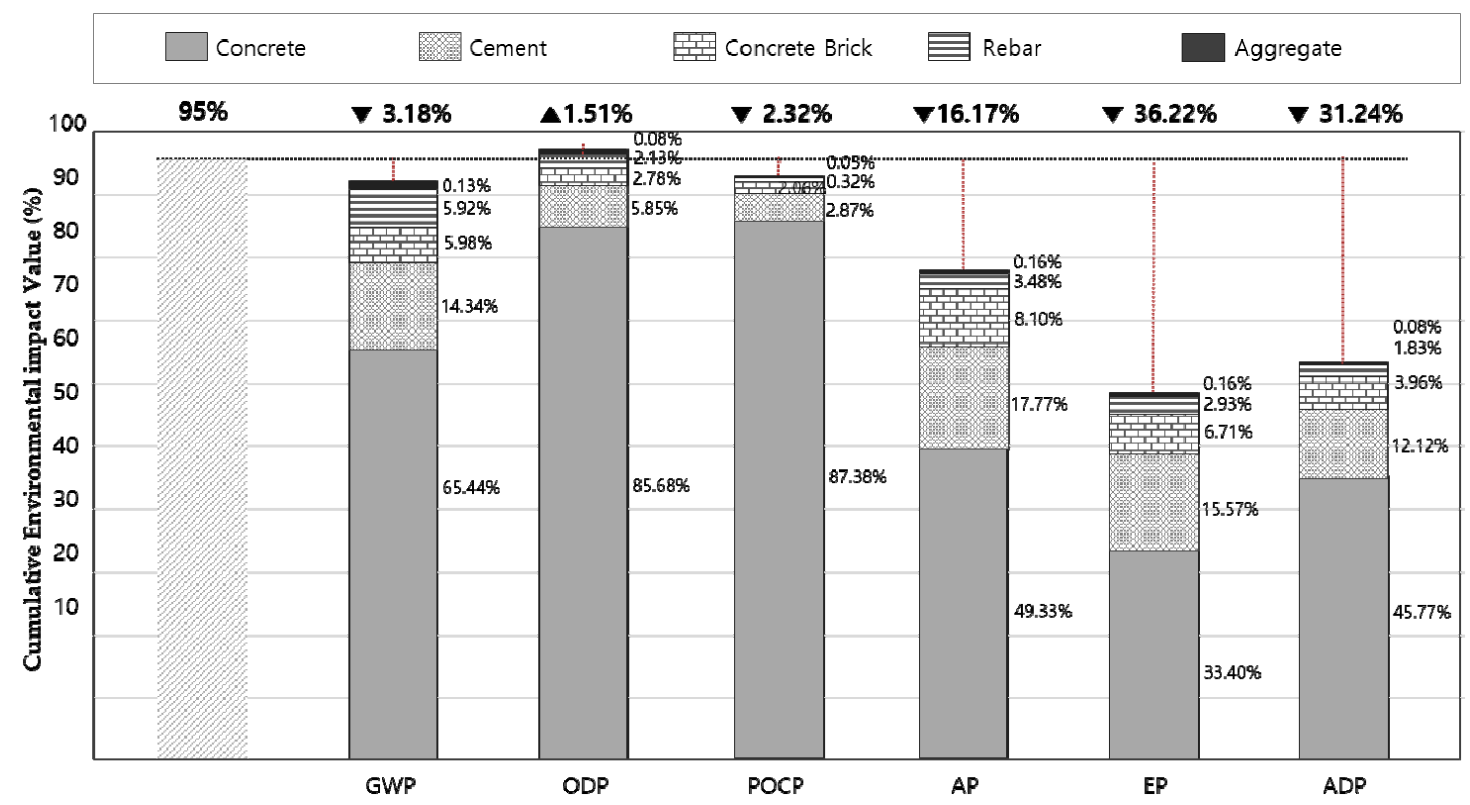

Figure 7. Cumulative contributions of the six types of environmental impact.

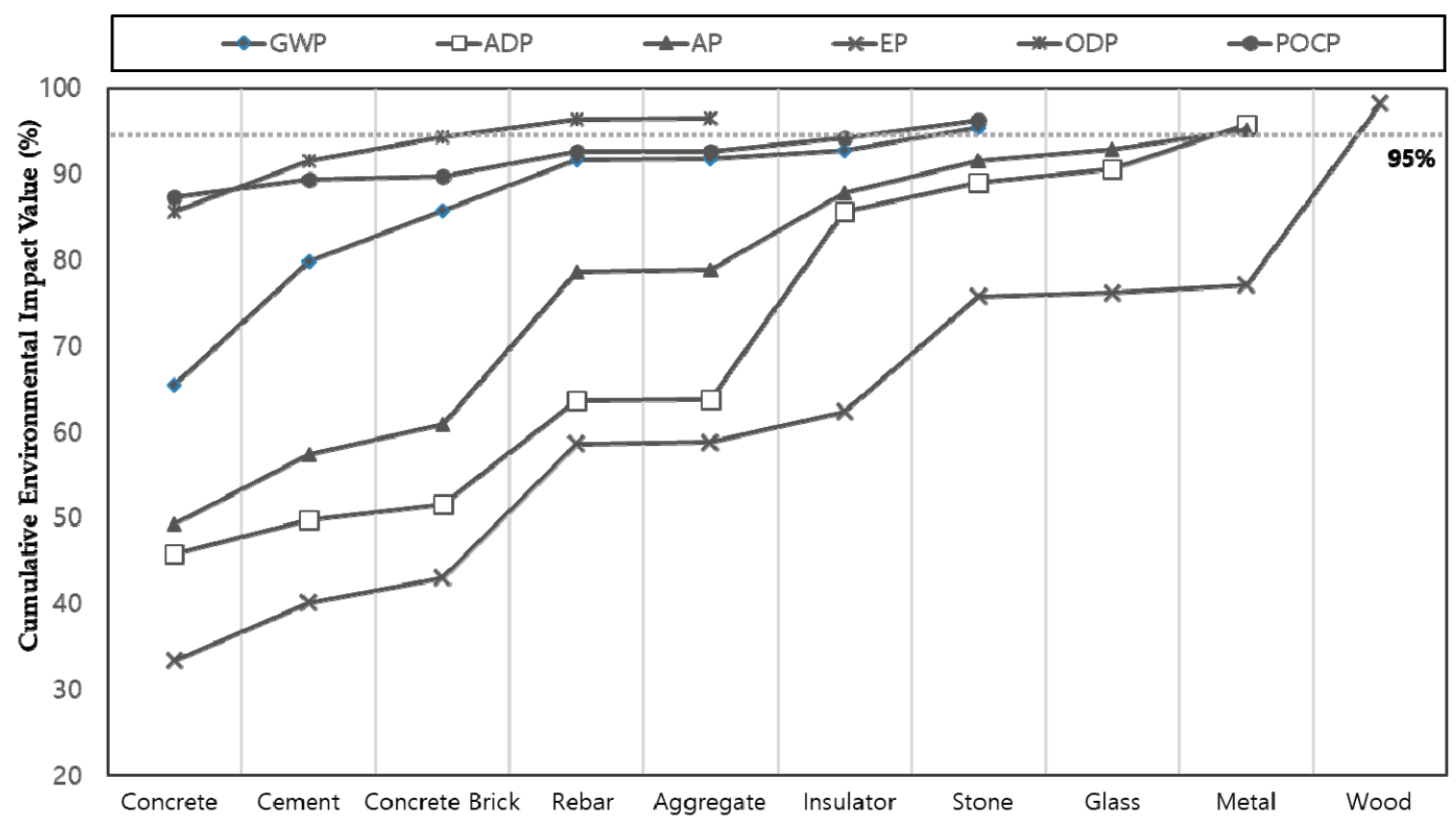

Figure 8. Six types of environmental impact values for primary building materials.

\section{Discussion}

Since a building consists of numerous types and quantities of building materials, it is difficult to assess these items properly during the design and production stage of a building owing to the frequency of design changes and limited availability of information. Therefore, at present, conducting an LCA is expensive in terms of time and financial cost, and certifications using the building LCA are extremely rare. Hence, using the results of this research, which focuses on establishing the main building materials used in non-residential buildings, efficient support can be achieved in terms of the cost and time while performing life cycle assessment at the early construction stage [37]. Furthermore, by analyzing the main building materials, which is the aim of this research, it becomes possible to analyze environmental effect assessment and possibility from the point of view of the building life 
cycle and to reduce the environmental effects per process markedly by using it. Moreover, it expedites sustainable production of eco-friendly buildings and the development of eco-friendly technology and materials. However, it is not enough to represent the main building materials for each category only by using the data analyzed to this point. To build the list of main standard building materials for each category, further analysis of more buildings must be performed and updated continuously. In addition to this, by analyzing the environmental effects of the established main building materials in this research, the applicability of the method was examined. From the results, it seems that not only building materials put in for the construction with high contribution levels based on the weight among the materials during the life cycle assessment of the buildings, but also the main input could be excluded from the analysis method of the weight standard. This includes materials such as insulators, metals, etc., which have significant environmental impact.

\section{Conclusions}

This study was conducted to support the building life cycle assessment (LCA) of G-SEED. Below are its conclusions.

The primary building materials applicable to streamlined LCA were selected to prepare a foundation for the building LCA of G-SEED. In this instance, the building usage and structural format were considered during the significance analysis of the building characteristics. As a result, five primary building materials were derived for school buildings in the RC structure, and five and six primary building materials were derived for office buildings in the RC and SRC structures, respectively. Four, five and six primary building materials were derived for commercial buildings in the SRC structure, accommodation buildings in the RC structure and general buildings in the RC structure, respectively.

To examine the applicability of the proposed primary building materials to the building LCA, a life cycle environmental impact assessment was performed by assessing a particular case and applying the unit values of the six primary environmental impact categories, namely GWP, AP, ADP, EP, ODP and POCP, to the primary building materials.

As a result of case assessment, the primary building materials derived based on weight exhibited significant values for GWP, ODP and POCP with error rates of less than 5\%. These findings are applicable to the environmental impact assessment requirements in an LCA.

Nowadays, countries are putting efforts to find a stable solution for sustainable development that can be achieved with an environmentally-friendly and resilient economic system. To this end, many people use renewable energy, reduce carbon emissions and find other ways to increase their adaptability to climate change [38]. This study proposed the criteria for an objective LCA to support the sustainable development in the construction sector. If such an LCA is performed based on the selected primary building materials, the LCA is more efficient in terms of both time and financial cost. Additionally, by analyzing the primary building materials, which is the aim of this research, it is possible to evaluate environmental effect assessment from the point of view of a building life cycle and to promote sustainable building production by reducing environmental impact in each construction phase. This will be a guideline for climate response that can reduce carbon emissions in the construction sector and enhance the climate resilience. However, for a more accurate assessment, it is also necessary to identify the primary building materials with high environmental impacts, but which may be excluded by the weight-based analysis method. In the future, it will be necessary to select primary building materials while considering both the weight-based cut-off criteria and the six environmental impact characterization values.

Author Contributions: This paper was written by H.L. and revised H.L. and S.R. S.T. designed and supervised the project.

Acknowledgments: This research was supported by the Basic Science Research Program through the National Research Foundation of Korea (NRF) funded by the Ministry of Science, ICT and Future Planning [No. 2015R1A5A1037548, No. 2015R1D1A1A01057925]. 
Conflicts of Interest: The authors declare no conflicts of interest.

\section{References}

1. Roh, S.-J.; Tae, S.-H.; Kim, T.H.; Kim, R.H. A study on the comparison of characterization of environmental impact of major building material for building life cycle assessment. J. Arch. Inst. Korea 2013, 29, 93-100.

2. Jeong, Y.S. Trend and analysis of domestic building energy consumption for reference building. J. Arch. Inst. Korea 2016, 36, 1375-1376.

3. Ahn, J. Study on Estimation of Environmental Load Production in Apartment Buildings through the Result of Major Materials Selection. Master's Thesis, Suwon University, Hwaseong, Korea, 2013.

4. Lee, N. A Study on the Analysis of Environmental Impact Factor for Building Major Materials in Countries to Support Green Building Certification. Master's Thesis, Hanyang University, Seoul, Korea, 2017.

5. UK Green Building Certification System BREEAM. Available online: http://www.breeam.org (accessed on 12 May 2018).

6. USA Green Building Certification System LEED. Available online: http:/ / www.gbci.org (accessed on 11 May 2018).

7. JAPAN Green Building Certification System CASBEE. Available online: http://www.ibec.or.jp (accessed on 16 May 2018).

8. South Korea Green Building Certification System G-SEED. Available online: http://www.g-seed.or.kr (accessed on 16 May 2018).

9. Korea Institute of Civil Engineering and Building Technology (KICT). Green Standard for Energy and Environmental Design (G-SEED); 2016 v1.2; Korea Institute of Civil Engineering and Building Technology: Goyang-si, Korea, 2016.

10. Chae, C.; Lee, K. Life cycle assessment on buildings using input-output analysis. Korean Soc. Life Cycle Assess. 2001, 1, 166-174.

11. Cho, H. Study on Building Environmental Load Management by Application of Life Cycle Assessment (LCA). Master's Thesis, Yonsei University, Seoul, Korea, 2001.

12. Lee, K.; Yang, J. A study on the functional unit estimation of energy consumption and carbon dioxide emission in the construction materials. J. Arch. Inst. Korea 2009, 25, 43-50.

13. Woo, J.; Shin, S. The environmental load comparison evaluation of the apartment house for main construction materials of standard apartment house. J. Korea Inst. Ecolog. Arch. Environ. 2010, 10, 85-90.

14. Kim, J.; Lee, S.; Son, J. An estimation of the energy consumption \& $\mathrm{CO}_{2}$ emission intensity during building construction. J. Arch. Inst. Korea 2004, 20, 319-326.

15. Choi, D.; Chun, H.; Ahn, J. Prediction of environmental load emissions from an apartment house of construction phase through the selection of major materials. J. Arch. Inst. Korea 2012, 28, 237-246.

16. Jeong, Y.; Choi, G.; Kang, J.; Lee, S. Development of a life cycle assessment program (K-LCA) for estimating environmental load of buildings. J. Arch. Inst. Korea 2008, 24, 259-266.

17. Roh, S.; Tae, S.; Baek, C.; Shin, S.; Lee, J.; Lee, J.; An, J. The development of object-oriented building life cycle $\mathrm{CO}_{2}$ assessment system (LOCAS). J. Arch. Inst. Korea 2012, 28, 101-108.

18. Ji, C.; Hong, T.; Jeong, J. Environmental impacts assessment of elementary school buildings and establishment of the reference target using life cycle assessment model. Korea, J. Constr. Eng. Manag. 2015, 16, 49-58. [CrossRef]

19. Kim, S.; Lim, S.; Jin, H.; Yang, I.; Lim, J.; Song, S. Estimation Method for Energy Consumption by End-Use in Office Building of Korea; The Society of Air-Conditioning and Refrigerating Engineers of Korea: Seoul, Korea, 2017; pp. 885-888.

20. Lim, S.; Jin, H.; Kim, S.; Lim, J.; Song, S. Preliminary Derivation of EUI and reference EUI of end-use energy consumption in office building. J. Arch. Inst. Korea 2017, 37, 441-442.

21. Kim, J.Y.; Kim, S.J.; Lee, S.M. An analysis on current status of certification for green building revitalization in school-Focused on the school located in Gyeonggi-do Province. Korea Inst. Sustain. Des. Educ. Environ. 2015, 14, 9-17. [CrossRef]

22. Ji, C.; Hong, T.; Jeong, J. Evaluation of life cycle energy consumption and $\mathrm{CO}_{2}$ emission of elementary school of buildings. Korea J. Constr. Eng. Manag. 2016, 17, 52-60. [CrossRef] 
23. Bae, C.; Kim, S.B.; Park, C.H.; Choo, S.Y. Studies on effectiveness proof of green building certification through the quantitative analysis of environmental performance of multi-residential buildings. J. Arch. Inst. Korea 2016, 32, 145-154. [CrossRef]

24. Hwang, S. A Study on the Score of Issues by Certification Grade in the G-SEED for Office Buildings. Master's Thesis, Daejeon University, Daejeon, Korea, 2016.

25. Kim, J. A Study on the Application Methodology of G-SEED through Life Cycle Assessment of Office Buildings. Ph.D. Thesis, Suwon University, Hwaseong, Korea, 2017.

26. Siew, R.Y.J.; Balatbat, M.C.A.; Carmichael, D.G. A review of building/infrastructure sustainability reporting tools (SRTs). SASBE 2013, 2, 106-139.

27. Citherlet, S.; Defaux, T. Energy and environmental comparison of three variants of a family house during its whole life span. Build. Environ. 2007, 42, 591-598. [CrossRef]

28. Daniel, K.; Hans, A. Relevance of simplifications in LCA of building components. Build. Environ. 2009, 44, 818-825.

29. Khasreen, M.; Banfill, P.; Menzies, G. life-cycle assessment and the environmental impact of buildings: A review. Sustainability 2009, 1, 674-701. [CrossRef]

30. ISO/FDIS 14040. Environmental Management-Life Cycle Assessment-Principles and Framework (2006); ISO: Geneva, Switzerland, 2006.

31. ISO/DIS 14041. Environmental Management_Life Cycle Assessment_Goal and Scope Definition and Inventory Analysis (2006); ISO: Geneva, Switzerland, 2006.

32. Lee, J.; Tae, S.; Kim, R. A Study on the analysis of $\mathrm{CO}_{2}$ emissions of apartment housing in the construction process. Sustainability 2018, 10, 365. [CrossRef]

33. Roh, S.; Tae, S.; Suk, S.J.; Ford, G. Evaluating the embodied environmental impacts of major building tasks and materials of apartment buildings in Korea. Renew. Sustain. Energy Rev. 2017, 73, 135-144. [CrossRef]

34. Korea Institute of Civil Engineering and Building Technology (KICT). Standard of Construction Estimate. 2018. Available online: http:/ / www.kict.re.kr (accessed on 1 May 2018).

35. Islam, H.; Jollands, M.; Setunge, S. Life cycle assessment and life cycle cost implication of residential buildings-A review. Renew. Sustain. Energy Rev. 2015, 42, 129-140. [CrossRef]

36. Korea Environmental Industry \& Technology Institute (KEITI). Life Cycle Assessment Inventory Database. Available online: www.epd.or.kr (accessed on 1 May 2018).

37. Kim, S.; Lee, S.; Na, Y.; Kim, J.T. Conceptual model for LCC-based $\mathrm{LCCO}_{2}$ analysis of apartment buildings. Energy Build. 2013, 64, 285-291. [CrossRef]

38. Castro Marins, K. Comparative assessment of sustainability strategies applied to urban neighbourhoods in Brazil, Germany and Sweden. Int. J. Sustain. Build. Technol. Urban Dev. 2017, 8, 195-207. 